\title{
Prevalence and preventability of adverse drug events in a teaching hospital: a cross-sectional study
}

R. Benkirane, ${ }^{1}$ A. Pariente, ${ }^{2}$ S. Achour, ${ }^{1}$ L. Ouammi, ${ }^{1}$ A. Azzouzi ${ }^{3}$ and R. Soulaymani ${ }^{1}$

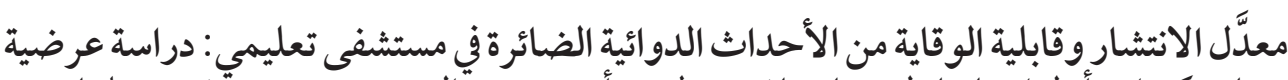

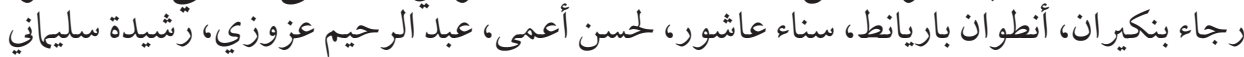

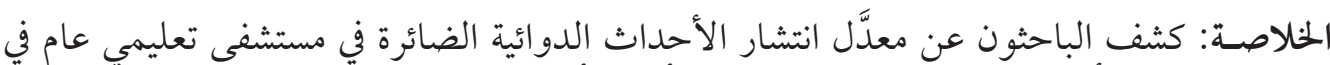

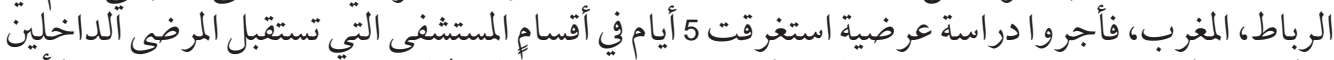

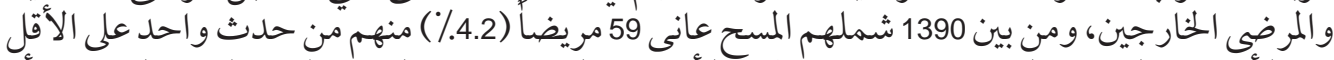

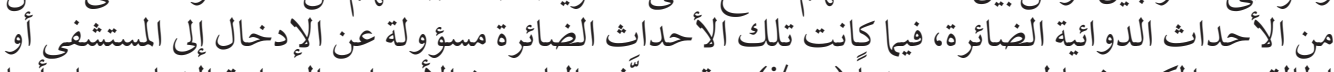

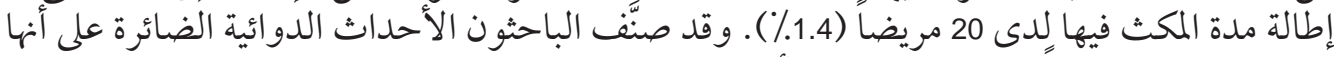

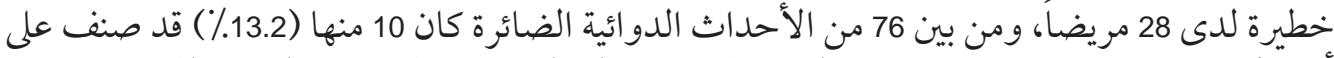



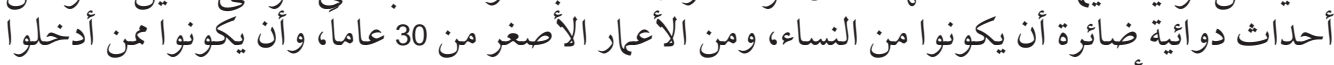
المستشفى في الأقسام الداخلية.

ABSTRACT We determined the prevalence of adverse drug events (ADEs) in a general teaching hospital in Rabat, Morocco. We performed a 5-day cross-sectional study of hospital departments recruiting inpatients and outpatients. Among the 1390 patients surveyed, 59 (4.2\%) experienced at least 1 ADE and for 20 patients (1.4\%) the ADE was responsible for hospitalization or prolongation of hospitalization. The ADE was classified as serious in 28 patients. Of the total of 76 ADEs, $10(13.2 \%)$ were categorized as preventable; 6 of these occurred during the treatment monitoring phase. Patients who experienced an ADE were more likely to be women, to be younger ( $<30$ years) and to be hospitalized in medical departments.

Prévalence et évitabilité des réactions indésirables aux médicaments dans un hôpital universitaire : une étude transversale

RÉSUMÉ Nous avons déterminé la prévalence des réactions indésirables aux médicaments (RIM) dans un hôpital général universitaire de Rabat (Maroc). Une étude transversale a été réalisée sur cinq jours dans les services accueillant des patients hospitalisés et ambulatoires. Parmi les 1390 patients étudiés, 59 (4,2\%) ont eu au moins une RIM et pour 20 patients (1,4\%), cette RIM était à l'origine de I'hospitalisation ou de la prolongation de l'hospitalisation. La RIM était considérée comme grave chez 28 patients. Sur un total de 76 RIM, 10 (13,2\%) étaient considérées comme évitables ; 6 d'entre elles s'étaient produites pendant la phase de surveillance du traitement. Les patients ayant eu une RIM étaient plutôt des femmes, des jeunes (moins de 30 ans) et des personnes hospitalisées dans des services de médecine.

\footnotetext{
${ }^{1}$ Moroccan Pharmacovigilance Centre, Rabat, Morocco (Correspondence to R. Benkirane: r_benkirane@ yahoo.fr).

${ }^{2}$ Regional Pharmacovigilance Centre, Aquitaine, Bordeaux, France.

${ }^{3} / \mathrm{bn}$ Sina Hospital, Rabat, Morocco.

Received: 13/11/06; accepted: 10/05/07
}

المجلة الصحية لشرق المتوسط، منظمة الصحة العالمية، المجلد الخامس عشر، العدد 0، 9 +. 


\section{Introduction}

Adverse drug events (ADEs) are when a patient is unintentionally harmed as a result of drug use, including preventable and non-preventable events [1]. Bates et al. estimated that $28 \%$ of ADEs in the United States were preventable [2]. ADEs can have major consequences including hospital admission, prolonged hospital stays, additional resource utilization and time lost from work, as well as lower patient satisfaction [3]. It has been estimated that ADEs lead to approximately $5 \%$ of all hospital admissions and occur during $10 \%$ to $20 \%$ of hospitalizations [4].

In developing countries, once access to care has been ensured for the population, improving the quality of health care delivery becomes an important concern. Ascertaining the prevalence of ADEs has been shown to be a useful indicator for this purpose [5]. Decreasing the prevalence of ADEs by implementing appropriate prevention strategies then constitutes a constant objective of every health care system.

The Moroccan Pharmacovigilance Centre (MPVC) was officially established in 1989 and is housed within the Poison Control Centre in Rabat. Collecting spontaneous reports of suspected ADEs remains its core activity. In 1992, the Moroccan centre was admitted as the 34 th national centre participating in the World Health Organization (WHO) Programme for International Drug Monitoring.

Since detailed knowledge is needed to design appropriate interventions, the MPVC initiated a study to evaluate the prevalence, seriousness and preventability of ADEs occurring in a sample of in- and outpatients receiving medications in one of the main hospitals of Morocco (Ibn Sina hospital).

\section{Methods}

\section{Study design and setting}

We performed a cross-sectional study over 5 days from 13 to 17 December 2004 in the Ibn Sina general teaching hospital in Rabat, Morocco. This hospital has a capacity of 1045 beds and approximately 15000 adult inpatients are admitted per year. This study was conducted by the MPVC in collaboration with the local drugs committee.

\section{Study population}

All patients admitted to Ibn Sina hospital between 13 and 17 December 2004 were eligible for inclusion in the study. Intentional drug overdose was not considered as an ADE and patients admitted for this reason were excluded from the study. All inpatient departments of the hospital-11 medical services, 11 surgical services, 3 intensive care units (ICUs) and 2 emergency unitsparticipated in the study.

\section{Data collection}

In each participating department, a medical resident was designated to collaborate with the MPVC's investigator for the detection of ADEs. A team of 15 investigators from the MPVC visited the 27 departments daily during the period of the study and solicited information from clinicians (especially the corresponding medical resident) concerning drug-related events.

For each patient, age, sex, diagnosis and admission department were recorded. Data were collected using the register of admission of the participating department and the patient's medical file. For each patient for whom an ADE was identified, clinicians completed a standardized form to record the demographic characteristics, medical history, treatment indications, nature of ADE, drugs involved, onset, delay and outcome. 


\section{Definitions}

The definition of ADE used in this study was "any injury resulting from medical interventions related to a drug" [6]. This included adverse drug reactions (ADRs), defined by the World Health Organization (WHO) as "any response to a drug which is noxious and unintended, and which occurs at doses normally used in humans for prophylaxis, diagnosis or therapy of disease, or for the modification of physiological function" [7]. The WHO definition implies that there was no error in the use of the drug [8] and the working definition of ADE therefore included both ADR, in which no error occurred, and complications that resulted from medication errors.

The seriousness of the ADE was also defined using WHO criteria. An ADE was considered serious if, at any dose, it resulted in death or was life-threatening, or required inpatient hospitalization or prolongation of existing hospitalization or resulted in persistent or significant disability/incapacity [7].

According to the time when the ADE occurred, patients were classified into 3 groups: patients without ADE, patients admitted for ADE or who had prolonged hospitalization due to an ADE, and patients who developed an ADE during their hospitalization.

ADE causality - the likelihood of a relationship between the drug and the eventwas assessed by 2 experienced investigators from the MPVC using the method and classification of Begaud et al., namely probable, very likely and doubtful [9].

The type of ADR was classified using the classification of Rawlins and Thompson as type A (augmented) when they were related to the pharmacological properties of drugs involved or type B (bizarre or idiosyncratic) if they were not [10].

Preventability was assessed according to a modified version of the criteria developed by Schumock and Thornton [11] and Winterstein et al. [12]. An ADE was classified as preventable if: the drugs involved were not appropriate for the patient's clinical condition; the dose, route or frequency of administration was not appropriate for the patient's age, weight or disease; the patient required therapeutic drug monitoring or other necessary laboratory tests that were not performed or not performed frequently enough; the patient had a history of allergy or previous reaction to the drug; a known drug interaction was the suspected cause of the reaction; a serum drug concentration above the therapeutic range was documented; non-compliance was associated with the reaction; or a medication error was associated with the reaction.

\section{Analysis}

The data were collated using Microsoft Excel software, version 5.1. Variables were described as percentages or mean and standard deviation (SD). Qualitative data were compared using the chi-squared test or Fisher exact test according to sample size. Quantitative data were compared using the Student $t$-test or Wilcoxon-Mann-Whitney $U$-test according to normality of their distributions. Prevalence rates of ADEs among all patients hospitalized in the participating departments during the study period were summarized as proportions with their $95 \%$ confidence interval (CI) estimated using the binomial distribution. The statistical significance level was set at $P<0.05$. Analysis was performed using Statistica, version 5 .

\section{Results}

During the 5 days we covered, 1390 patients were included in the study: 840 men and 550 women. The mean age of the pa-

المجلة الصحية لشرق المتوسط، منظمة الصحة العالمية، المجلد الخامس عشر، العدد 0،9 +.ب 
tients was 44.3 (SD 15.4) years. Among these, $39.7 \%$ were admitted to medical departments, $39.0 \%$ to surgical departments, $18.4 \%$ to emergency departments and $2.9 \%$ to ICUs.

There were 59 patients who experienced at least $1 \mathrm{ADE}$, giving an estimated prevalence of ADE of $4.2 \%$ (95\% CI: $3.9 \%-4.4 \%)$. These patients were significantly more likely to be women $(55.9 \%$ of ADE patients versus $43.2 \%$ for the whole cohort, $P=0.012$ ). They also tended to be younger, with a mean age of 44.3 (SD 15.4) years versus 46.3 (17.7) years for the whole cohort (Table 1), although this difference was not statistically significant.

The prevalence of ADEs by hospital department was $7.5 \%$ in ICUs, $6.7 \%$ in medical departments, 3.9\% in emergency departments and $1.5 \%$ in surgical departments (Table 2). The highest rate was in the nephrology unit, where 6/27 (22.2\%) patients suffered an ADE.

There were 20 patients who were admitted or had prolonged hospitalization due to an ADE, a prevalence of $1.4 \%(95 \%$ CI: $0.8 \%-2.0 \%$ ) (Table 2). The ADE was classified as serious for 28 patients $(2.0 \%$ of all patients; $47.5 \%$ of ADE patients (13 leading to hospitalization, 7 prolonging hospitalization, 5 life-threatening, 2 resulting in permanent disability, 1 fatal) (Table 2). The prevalence of serious ADEs among patients was estimated at 2.0\% (95\% CI: $1.3 \%-2.7 \%$ ) and the fatality rate was $0.07 \%$ (1 death related to ADE among 1390 monitored patients). In addition to the patient who died, 2 patients suffered serious sequelae (pulmonary fibrosis related to amiodarone; cutaneous sequelae related to vasculitis induced by interferon). For the others, the outcome after 1 month was

\begin{tabular}{|c|c|c|c|c|c|}
\hline Variable & Patie & th ADE & & & $P$-value \\
\hline \multirow[t]{2}{*}{ Mean (SD) age (years) } & \multicolumn{2}{|c|}{$44.3(15.4)$} & \multicolumn{2}{|c|}{$46.3(17.7)$} & 0.43 \\
\hline & No. & $\%$ & No. & $\%$ & \\
\hline \multicolumn{6}{|l|}{ Age $\left(\right.$ years) ${ }^{a}$} \\
\hline$<30$ & 21 & 35.6 & 243 & 20.3 & 0.004 \\
\hline $30-39$ & 8 & 13.6 & 198 & 16.5 & 0.512 \\
\hline $40-49$ & 11 & 18.6 & 227 & 19.0 & 0.903 \\
\hline $50-59$ & 11 & 18.6 & 210 & 17.5 & 0.626 \\
\hline $60-69$ & 5 & 8.5 & 176 & 14.7 & 0.170 \\
\hline$>70$ & 3 & 5.1 & 143 & 11.9 & $0.152^{b}$ \\
\hline \multicolumn{6}{|l|}{ Sex } \\
\hline Female & 33 & 55.9 & 517 & 43.2 & 0.012 \\
\hline Male & 26 & 44.1 & 814 & 68.0 & \\
\hline \multicolumn{6}{|l|}{ Hospital department } \\
\hline Medical & 37 & 62.7 & 515 & 43.0 & \\
\hline $\begin{array}{l}\text { Other (surgical, intensive } \\
\text { care, emergency) }\end{array}$ & 22 & 37.3 & 816 & 68.2 & $<0.001$ \\
\hline
\end{tabular}

${ }^{a}$ Age not recorded for 134 patients; ${ }^{b}$ Yates correction.

$S D=$ standard deviation. 


\begin{tabular}{|c|c|c|c|c|c|c|c|}
\hline \multirow[t]{2}{*}{$\begin{array}{l}\text { Hospital department/ } \\
\text { ward }\end{array}$} & \multirow{2}{*}{$\begin{array}{c}\text { Total } \\
\text { inpatients } \\
\text { No. }\end{array}$} & \multicolumn{2}{|c|}{ Patients with ADE } & \multicolumn{2}{|c|}{$\begin{array}{l}\text { Patients admitted } \\
\text { for ADE/prolonged } \\
\text { hospitalization } \\
\text { due to ADE }\end{array}$} & \multicolumn{2}{|c|}{$\begin{array}{c}\text { Patients } \\
\text { developing } \\
\text { serious ADE }\end{array}$} \\
\hline & & No. & $\begin{array}{l}\% \text { of } \\
\text { total }\end{array}$ & No. & $\begin{array}{l}\% \text { of } \\
\text { total }\end{array}$ & No. & $\%^{a}$ \\
\hline Medical departments & 552 & 37 & 6.7 & 11 & 2.0 & 16 & 43.2 \\
\hline Nephrology & 27 & 6 & 22.2 & - & - & 1 & 16.7 \\
\hline Haemodialysis & 104 & 4 & 3.8 & - & - & 4 & 100.0 \\
\hline Endocrinology & 33 & - & - & - & - & - & - \\
\hline Dermatology & 22 & 2 & 9.1 & 2 & 9.1 & 2 & 100.0 \\
\hline Digestive exploration & 58 & 5 & 8.6 & - & - & - & - \\
\hline Internal medicine & 54 & 5 & 9.3 & 3 & 5.6 & 3 & 60.0 \\
\hline Gastroenterology & 125 & 10 & 8.0 & 4 & - & 4 & 40.0 \\
\hline General medicine & 44 & 2 & 4.5 & 1 & 2.3 & 1 & 50.0 \\
\hline Cardiology & 59 & 3 & 5.1 & 1 & 1.7 & 1 & 33.3 \\
\hline Pneumology & 26 & - & - & - & - & - & - \\
\hline Intensive care units & 40 & 3 & 7.5 & 2 & 5.0 & 2 & 66.6 \\
\hline Medical & 14 & 2 & 14.3 & 1 & 7.1 & 1 & 50.0 \\
\hline Surgical & 26 & 1 & 11.1 & 1 & 11.1 & 1 & 100.0 \\
\hline Emergency departments & 256 & 10 & 3.9 & 6 & 2.3 & 6 & 60.0 \\
\hline Medical & 200 & 10 & 5.0 & 6 & 2.3 & 6 & 60.0 \\
\hline Surgical & 56 & - & - & - & - & - & - \\
\hline Surgical departments & 542 & 8 & 1.5 & 1 & 0.2 & 4 & 50.0 \\
\hline Trauma & 71 & 2 & 2.8 & 1 & 0.2 & 1 & 50.0 \\
\hline Thoracic surgery & 29 & - & - & - & - & - & - \\
\hline Cardiovascular & 23 & - & - & - & - & - & - \\
\hline Digestive surgery & 65 & 1 & 1.5 & - & - & 1 & 100.0 \\
\hline General surgery & 59 & 1 & 1.7 & - & - & 1 & 100.0 \\
\hline Surgery ${ }^{b}$ & 70 & - & - & - & - & - & - \\
\hline Vascular surgery & 45 & - & - & - & - & - & - \\
\hline Neurosurgery & 46 & - & - & - & - & - & - \\
\hline Urology & 110 & 1 & 0.9 & - & - & - & - \\
\hline Plastic surgery & 24 & 3 & 12.5 & - & - & 1 & 33.3 \\
\hline Total & 1390 & 59 & 4.2 & 20 & 1.4 & 28 & 47.5 \\
\hline
\end{tabular}

${ }^{a}$ of patients with $A D E ;{ }^{b}$ Emergency visceral surgery unit.

favourable in $89.8 \%$ of patients, stable in $5.1 \%$ and unknown in $5.1 \%$.

A total of 76 ADEs were observed in the 59 patients. The global ADE prevalence was then estimated at 5.5\% (95\% CI: $4.7 \%-7.1 \%)$. The organ systems most frequently affected by ADEs were gastrointestinal $(26.3 \%)$, cutaneous $(21.0 \%)$, neurological (9.2\%), haematological (7.9\%) and respiratory $(6.6 \%)$ (Table 3$)$. The drug classes most frequently involved were analgesics (excluding nonsteroidal antiinflammatories) $(17.1 \%)$, anti-inflammatories $(11.8 \%)$, antibiotics $(6.6 \%)$, anticoagulants $(5.2 \%)$ and psychoactive drugs $(5.3 \%)$.

المجلة الصحية لشرق المتوسط، منظمة الصحة العالمية، المجلد الخامس عشر، العدد 0، 9 ب. 
Regarding causality of the 76 ADEs, $67 \%$ were assessed as probable, $6 \%$ very likely and $27 \%$ doubtful. Identified ADEs were classified as type A ADR (related to the pharmacological properties of the drugs) in $80.3 \%$ and type B ADR (bizarre or idiosyncratic) in $19.7 \%$.

There were 10 ADEs (13.2\%) that were considered preventable: 6 cases were associated with insufficient monitoring by laboratory testing or other investigations. Other preventable ADEs included 1 case of serious abdominal haematoma resulting from an excessive anticoagulation, 2 cases due to persistence of antiseptic in a haemodialysis tube and 1 case of agitation in a patient who was prescribed an antidepressant without an associated anxiolytic (Table 4).

\section{Discussion}

This study confirms that ADEs represent a non-negligible disease burden in hospitalized patients. Our data show that $4.2 \%$ of inpatients experienced 1 or more ADE, with a global prevalence estimated at 5.5\%. A similar cross-sectional study conducted on a given day in the Bichat-Claude Bernard hospital group in Paris, found that $6.3 \%$ of the patients exhibited at least $1 \mathrm{ADE}$ during their hospitalization, with a global prevalence of $9.9 \%$ [13].

The prevalence obtained in the present study agrees with the values obtained in several studies. A wide range of rates have been reported in the literature, suggesting that ADEs occur in $0.7 \%-6.5 \%$ of inpatients [1]. It is difficult to compare these reported frequencies because of different settings, different data collection methods and discrepancies in the underlying definition of ADE. Estimation of ADE prevalence has to deal with underreporting, which is a huge problem in drug safety. Differences in underreporting rates cannot be excluded in existing studies and could partly explain the differences observed between the prevalence estimates.

On assessing the prevalence by department (medical, surgical, ICU and emergency), we found that the highest rate was recorded in the ICU. Cullen et al. in their comparative study on the detection of preventable and potential ADEs, found that the prevalence in the ICU was nearly twice the rate of non-ICU departments [14]. Patients in ICUs may be at higher risk of ADEs because of their greater exposure to medications and because their health state is weaker than other patients.

As shown in several studies $[12,13,15]$, a high proportion of ADEs are reported in medical departments. The prevalence varied among departments, the highest being registered in the nephrology unit, which could reflect the importance of renal impairment in the occurrence of ADEs.

In our study, women had a higher risk of ADEs, which is consistent with previous studies. Even though patients who experienced ADEs tended to be younger, there was no statistically significant difference between the mean age of patients with or without ADE. Nevertheless, we found that patients aged less than 30 years had a significantly higher risk of ADE. This could reflect the fact that young people tend to self-medicate more than older people, but the demographic distribution of age in the Moroccan population could also explain this result; according to the national census of 2004, people aged under 35 years represented $64.3 \%$ of the population [16].

The organ systems most often affected were gastrointestinal and dermatological, which is commonly described in the literature [17]. In our study, the drug classes most frequently associated with ADEs were analgesics, anti-inflammatories, antibiotics, anticoagulants and psychoactive drugs, 


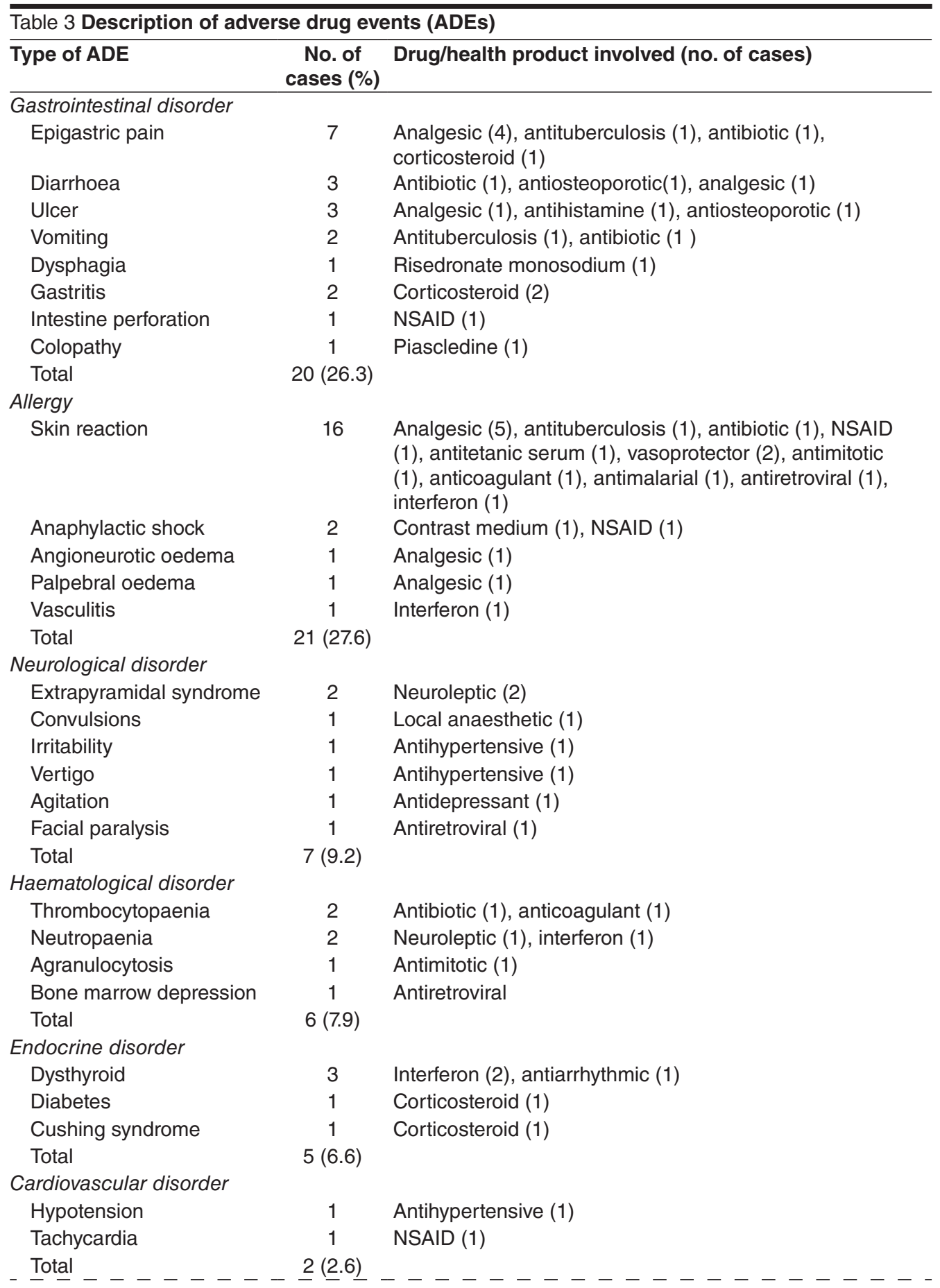




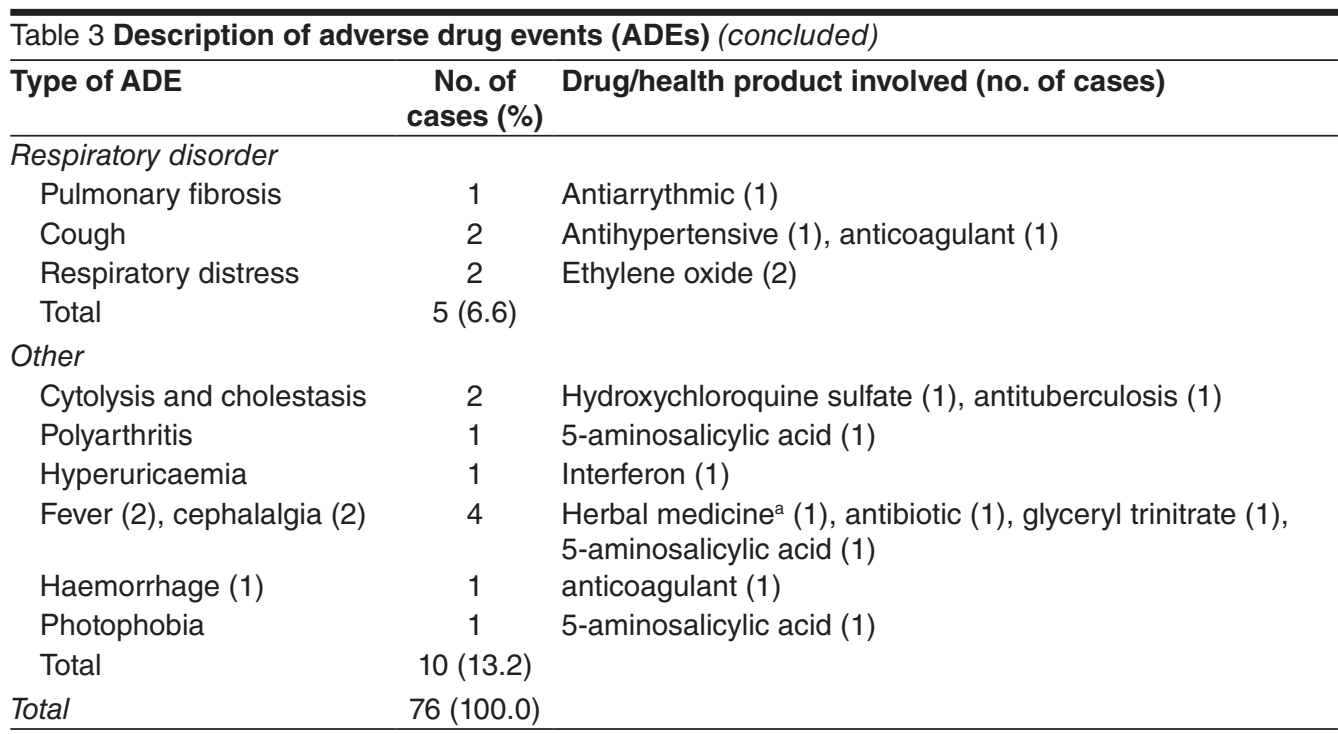

${ }^{a}$ Lawsonia inermis

NSAID = nonsteroidal anti-inflammatory drug.

which is consistent with some other studies $[12,15]$.

After causality assessment, almost twothirds of the identified ADEs were judged to have a "reasonable" link with drug intake. Almost half of the recorded ADEs were serious $(47.5 \%)$, with a fatality rate estimated at $0.07 \%$. The higher proportion of serious events in our study might reflect the fact that teaching hospitals recruit more seriously ill patients than non-teaching hospitals [18].

The rate of preventable ADE was evaluated as $13.2 \%$, which appears lower than estimations already available in the literature. The median preventability rate reported by Kanjanarat et al. in a review of the literature, was $35.2 \%$ (ranging from $18.7 \%$ to $73.2 \%$ ) [19]. A possible explanation for the low rate of preventable ADE observed in our study may be the method used to identify preventable ADEs and the short period of the survey (5 days). In contrast with previous studies that mainly ascertained preventable ADEs using hospital chart review, our cases were collected in collaboration with clinicians, and we cannot exclude a selective underreporting of ADEs perceived as personal error by clinicians. Most cases of preventable ADEs $(60 \%)$ could be related to insufficient drug monitoring. Gurwitz et al. found that preventable ADEs occurred most often at the stages of ordering and monitoring of drugs [20] and Bates et al. reported that preventable ADEs most often occur at the stages of ordering $(56 \%)$ and administration (34\%) [2].

Our study has several limitations. The short period of the survey might lead to underestimation of the real ADE prevalence rate. The method used for identification of preventable ADEs was based on physician interview and might be sensitive to underreporting, which could have lead to underestimation of the rates of ADE and preventable ADE. Nevertheless, the reporting rate for the study appeared to be high, as 76 ADEs were reported during the 5-day study period, when there are usually only around 


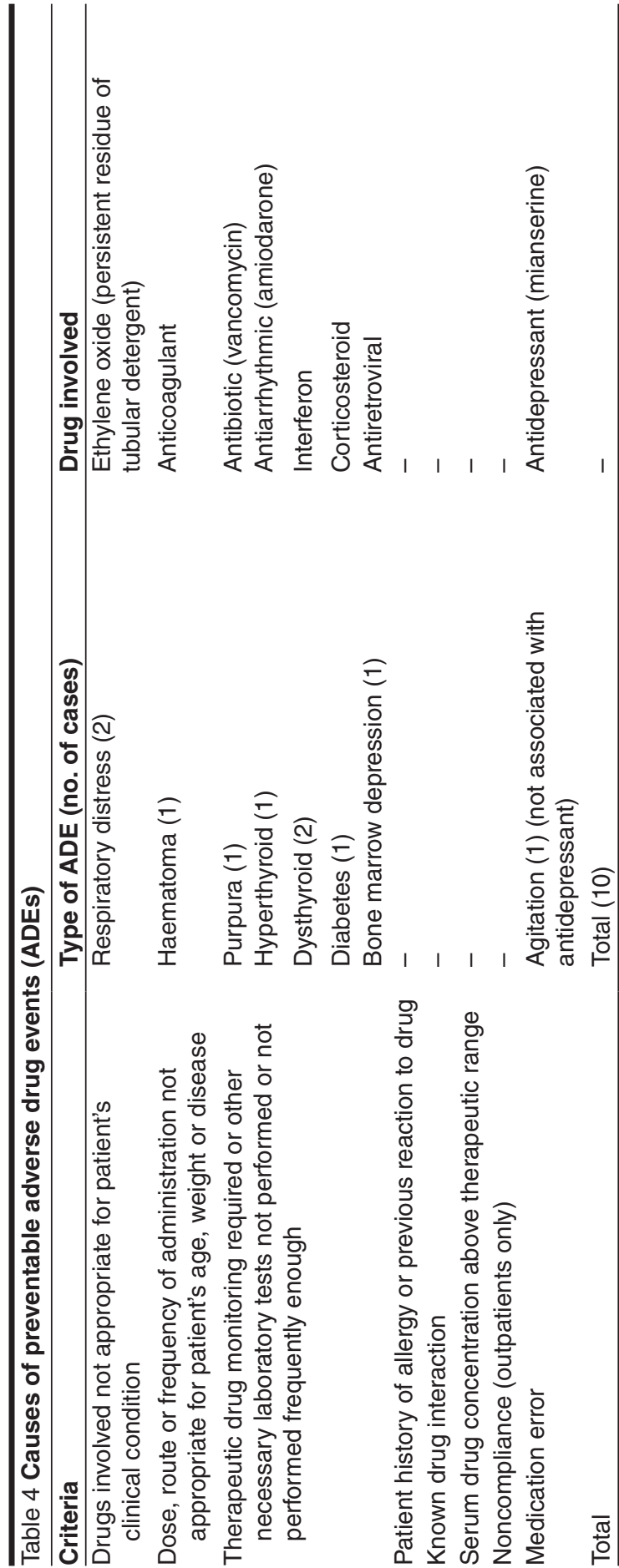

200 reports per year received from this hospital at the MPVC. Thus, a sustained sensitization of health professionals is needed to reinforce the spontaneous reports, and to strengthen the notification circuit to improve collaboration between hospitals and the MPVC.

The results of our study might help in designing prevention measures to decrease the prevalence of ADEs. Promoting increased awareness of ADEs and enforcement of existing recommendations on drug monitoring are a priority in this objective, considering the high proportion of ADEs that could be prevented by better monitoring. These results are also important to help health care professionals recognize the extent of the burden of care that can be related to ADEs, and to be conscious of the need for better research, identification and reporting of ADEs.

\section{Conclusion}

Our study confirms the substantial rate of morbidity associated with medicine use and contributes to promoting pharmacovigilance in the medical and paramedical community. It suggests that accurate information on ADEs in hospital is needed. It provides a starting point for understanding the prevalence of ADEs and preventable ADEs in Moroccan hospitals. However, additional work is needed to explore preventable ADEs and their contributing factors further and to develop strategies aimed at their prevention. 


\section{Acknowledgements}

We thank all the health professionals of Ibn Sina for their active collaboration. We also thank the Moroccan Pharmacovigilance and Poison Control Centre team who contributed to the study.
No sources of funding were used to assist in the preparation of this study.

The authors have no conflicts of interest directly relevant to the content of this manuscript.

\section{References}

1. Dean B. Drug events: what's the truth? Quality and safety in health care, 2003, 12:165.

2. Bates DW et al. Incidence of adverse drug events and potential adverse drug events. Implications for prevention ADE Prevention Study Group. Journal of the American Medical Association, 1995, 274:29-34.

3. Morimoto $\mathrm{T}$ et al. Adverse drug events and medication errors: detection and classification methods. Quality and safety in health care, 2004, 13:306-14.

4. Hardmeier B et al. Adverse drug events caused by medication errors in medical inpatients. Swiss medical weekly, 2004, 134:664-70.

5. Baker GR et al. The Canadian adverse events study: the incidence of adverse events among hospital patients in Canada. Journal of Ayub Medical College, 2004, 170(11):1678-86.

6. Bates DW et al. Relationship between medication errors and adverse drug events. Journal of general internal medicine, 1995, 10:199-205.

7. WHO Collaborating Centre for International Drug Monitoring. Safety monitoring of medicinal products: guidelines for setting up and running a pharmacovigilance centre. London, EQUUS, 2000.

8. Leape LL et al. Systems analysis of adverse drug events. Journal of the American Medical Association, 1995, 274:35-43.

9. Begaud B et al. Imputabilité des effets inattendus ou toxiques des médicaments [Ac- countability of unexpected or toxic effects of drugs]. Thérapie, 1985, 40:111-8.

10. Rawlins MD, Thompson JW. Mechanisms of adverse drug reactions. In: Davies DM, ed. Textbook of adverse drug reactions. Oxford, Oxford University Press, 1991:18-45.

11. Schumock GT, Thornton JP. Focusing on the preventability of adverse drug reactions. Hospital pharmacy, 1992, 27:538.

12. Winterstein $A G$ et al. Identifying clinically significant preventable adverse drug events through a hospital's database of adverse drug reaction reports. American journal of health-system pharmacy, 2002, 59:1742-9.

13. Baune B et al. latrogénie médicamenteuse à l'hôpital: enquête d'un jour donné [Medicinal iatrogenics in hospitals: a survey on a given day]. La Presse médicale, 2003, 32:683-8.

14. Cullen DJ et al. Preventable adverse drug events in hospitalized patients: A comparative study of intensive care and general care units. Critical care medicine, 1997, 25(8):1289-97.

15. Bates DW et al. Patient risk factors for adverse drug events in hospitalized patients. Archives of internal medicine, 1999, 159:2553-60.

16. National census of 2004. Rabat, Morocco, Directorate General of Statistics, Ministry of Economic Forecasting and Planning, 2004. 
17. Suh DC et al. Clinical and economic impact of adverse drug reactions in hospitalized patients. Annals of pharmacotherapy, 2000, 34(12):1373-9.

18. Lazarou J, Promeranz BH, Corey PN. Incidence of adverse drug reactions in hospitalized patients: a meta-analysis of prospective studies. Journal of the American Medical Association, 1998, 279:1200-5.
19. Kanjanarat $P$ et al. Nature of preventable adverse drug events in hospitals: a literature review. American journal of healthsystem pharmacy, 2003, 60:1750-9.

20. Gurwitz JH et al. The incidence of ADE in two large academic long-term care facilities. American journal of medicine, 2005, 118(3):251-8.

\section{The safety of medicines: adverse drug reactions (ADRs)}

It is estimated that at least $60 \%$ of ADRs are preventable. The risk of harm can be minimized by ensuring that prescribed medicines are of good quality, safe, effective and used by the right patient in the right dose at the right time.

WHO promotes global drug safety through its International Drug Monitoring Programme, which began in the 1960s. Through the cooperative effort, Member States and WHO work together to identify possible relationships between the use of a drug and adverse effects. Mearly 100 countries now have national systems in place to report ADRs to the database managed by the WHO Collaborating Centre, the Uppsala Monitoring Centre. When signals of drug safety problems emerge, WHO shares the results with all Member countries.

Source: WHO Fact sheet $N^{\circ} 293$

Updated October 2008

(http://www.who.int/mediacentre/factsheets/fs293/en/) 